\title{
PENGARUH ACADEMIC EMOTIONS DAN SCHOOL BELONGING TERHADAP STUDENTS'LIFE SATISFACTION PADA SISWA MENENGAH PERTAMA
}

\author{
Raden Wachyu Zakia Fadilah, Sri Maslihah, Ifa Hanifah Misbach
}

Departemen Psikologi, Universitas Pendidikan Indonesia

Email:ya_ayuzakia@rocketmail.com,maslihah_psi@upi.edu,ifahmisbach@gmail.com

\begin{abstract}
The aim of this study was to determine the influence of academic emotions and school belonging toward students' life satisfaction of students of state junior high school in Bandung. The approach used is a quantitative approach by using causality technique research. Cluster random sampling used as sampling technique. 471 students of state junior high school in Bandung completed the adaptation of Achievement Emotions Questionnaire (AEQ), adaptation of Psychological Sense of School Membership (PSSM), and adaptation of Multidimensional Students' Life Satisfaction Scale (MSLSS). Analyses using linear and multiple regression revealed (1) there is a significant effect of positive academic emotions to students' life satisfaction, (2) there is a significant effect of negative academic emotions to students' life satisfaction,(3) there is a significant effect of school belonging to students' life satisfaction, (4) there is a significant effect of positive academic emotions and school belonging to students' life satisfaction, and (5) there is a significant effect of negative academic emotions and school belonging to students' life satisfaction.
\end{abstract}

Keywords: academic emotions, students' life satisfaction, school belonging

\begin{abstract}
Abstrak
Penelitian ini bertujuan untuk mengetahui pengaruh academic emotions dan school belonging terhadap students' life satisfaction pada siswa SMP. Penelitian ini adalah pendekatan kuantitatif dengan teknik penelitian kausalitas. Cluster random sampling digunakan sebagai teknik sampling. 471 siswa SMP Negeri kota Bandung mengisi kuesioner berupa instrumen Achievement Emotions Questionnaire (AEQ), Psychological Sense of School Membership (PSSM), dan Multidimensional Students' Life Satisfaction Scale (MSLSS). Teknik analisis data yang digunakan adalah regresi linear dan regresi berganda. Hasil penelitian menunjukkan bahwa (1) terdapat pengaruh yang signifikan dari positive academic emotions terhadap students' life satisfaction, (2) terdapat pengaruh yang signifikan dari negative academic emotions terhadap students' life satisfaction, (3) terdapat pengaruh yang signifikan dari school belonging terhadap students' life satisfaction, (4) terdapat pengaruh yang signifikan dari positive academic emotions dan school belonging terhadap students' life satisfaction, dan (5) terdapat pengaruh yang signifikan dari negative academic emotions dan school belonging terhadap students' life satisfaction pada siswa SMP Negeri kota Bandung.
\end{abstract}

Kata Kunci: academic emotions, students' life satisfaction, school belonging 


\section{PENDAHULUAN}

Masa remaja diawali pada usia 10-12 tahun hingga 18-21 tahun (Santrock, 2011). Pada awal masa remaja atau sekitar usia 12-14 tahun sebagian besar anak sedang berada pada tingkat pendidikan Sekolah Menengah Pertama (SMP). Siswa SMP ini sedang mengalami berbagai perubahan mulai dari telah mampu berpikir abstrak dan mengalami pubertas (APA, 2002). Pubertas yang dialami ini berdampak pada keadaan emosi remaja menjadi tidak begitu stabil sehingga terkadang mereka merasa sangat bersemangat namun tidak lama kemudian mereka merasa begitu putus asa (Pandey, Dave, \& Chandra, 2017).

Siswa SMP juga dikatakan tengah berada dalam masa untuk berubah, mengeksplorasi, bergembira sekaligus sebagai moment mencari identitas diri atau menelusuri lebih jauh mengenai siapa dirinya (Coon \& Mitterer, 2014). Seorang remaja tidak lagi menjelaskan dirinya sebagai seseorang yang memiliki rambut pendek/panjang, berkulit putih/coklat, atau bertubuh tinggi/pendek, melainkan menjelaskannya dengan hal-hal yang lebih abstrak seperti jujur, ramah, bahagia (Shaffer \& Kipp, 2010), atau menggunakan konsep kepuasan hidupnya. Kepuasan hidup atau life satisfaction adalah bagaimana seseorang mengevaluasi kualitas kehidupannya yang dapat dilihat dari beberapa domain mulai dari diri sendiri, keluarga, teman-teman, lingkungan tempat tinggal, dan sekolah (Huebner, 1991; Huebner, Laughlin, Ash, \& Gilman, 1998).

Seperti yang telah disebutkan di atas bahwa sekolah menjadi salah satu domain yang menentukan kepuasan hidup seorang siswa. Hal ini terjadi karena lingkungan sekolah menjadi lingkungan mikrosistem atau lingkungan yang berinteraksi langsung dengan siswa (Na'imah, 2012). Di sekolah siswa banyak menghabiskan waktu dengan guru dan temantemannya yang mana menjadi bagian penting dalam pertumbuhan siswa termasuk dalam bagaimana siswa memandang kepuasan hidupnya (McCabe, Bray, Kehle, Theodore, \& Gelbar, 2011).

Sebuah penelitian menunjukkan bahwa iklim sekolah yang terdiri dari hubungan siswa dengan teman, hubungan siswa dengan guru, dan lingkungan fisik sekolah ternyata berkorelasi positif dengan kepuasan hidup siswa (Baș \& Yurdabakan, 2017; Suldo, Thalji-Raitano, Hasemeyer, Gelley, \& Hoy, 2013).

Kepuasan hidup siswa dianggap menjadi hal yang penting karena dapat memberi efek positif terhadap prestasi akademik, perilaku siswa, dan keadaan sosioemosional siswa (Suldo dkk., 2013). Hal ini terbukti dengan didapatkannya hasil penelitian yang menyatakan bahwa kepuasan hidup berkorelasi dengan emosi positif, emosi negatif, dan depresi (Durak, SenolDurak, \& Gencoz, 2010). Adapun emosi positif dan emosi negatif yang berhubungan langsung dengan proses belajar, aktivitas di kelas, dan proses meraih prestasi yaitu academic emotions (Goetz dkk., 2014). Berdasarkan valensinya emosi terbagi menjadi emosi positif dan negatif (Pekrun, Goetz, Titz, \& Perry, 2002a). Contoh emosi positif adalah kenikmatan (enjoyment), harapan (hope), bangga (pride), dan lega (relief). Sedangkan contoh emosi 
negatif adalah marah (anger), gelisah (anxiety), malu (shame), putus asa (hopelessness), dan bosan (boredom) (Pekrun, Goetz, Titz, \& Perry, 2002b).

Emosi dapat dilihat dari sisi kontekstual yaitu class-related emotions (emosi yang berkaitan dengan kelas), learning-related emotions (emosi yang berkaitan dengan belajar), dan test-related emotions (emosi yang berkaitan dengan tes). Emosi yang berkaitan dengan kelas menjelaskan emosi apa saja yang dirasakan oleh siswa sebelum berada di kelas, selama berada di kelas, dan sesudah berada di kelas atau sesudah masa pembelajaran. Sedangkan emosi yang berkaitan dengan belajar mengacu pada emosi-emosi yang dirasakan oleh siswa baik itu sebelum belajar, ketika belajar, maupun setelah belajar. Adapun emosi yang berkaitan dengan tes merujuk pada emosi-emosi yang dirasakan oleh siswa berkaitan dengan tes atau ujian. Mulai dari sebelum diselenggarakannya ujian, selama ujian berlangsung, dan setelah ujian dilaksanakan (Pekrun, Goetz, Titz, \& Perry, 2002b).

Beberapa penelitian menyebutkan seseorang akan merasa puas dengan hidupnya jika mereka banyak mengalami emosi positif (Kööts-Ausmees, Realo, \& Allik, 2013; Kuppens, Realo, \& Diener, 2008). Hal ini ditegaskan juga oleh penelitian yang dilakukan terhadap 266 mahasiswa dari tiga universitas di Cina. Penelitian tersebut memperoleh hasil bahwa emosi positif dapat memengaruhi kepuasan hidup yang dimediasi dan dimoderasi oleh kebermakanaan hidup (meaning in life) (Li \& Zhao, 2014).

Kehidupan siswa di sekolah berkaitan juga dengan interaksi yang terjalin dengan teman, guru, dan petugas sekolah. Siswa yang memiliki hubungan sosial yang positif dengan teman, guru, dan petugas sekolah, dan apabila ia merasa puas dengan kehidupannya, maka besar kecenderungannya siswa tersebut akan menunjukkan perilaku positif terhadap berbagai pihak di sekolah (Seyitoğlu \& Çevik, 2016). Dalam penjelasannya disebutkan bahwa hal ini berdampak pada sense of school belonging pada siswa. Sense of school belonging adalah perasaan diterima, dihargai, dianggap, dan didukung oleh seluruh anggota lingkungan sekolah (Goodenow, 1993; Hughes, Im, \& Allee, 2016). School belonging ini dapat dilihat dari perasaan disukai, diterima secara personal, dan diikutsertakan; perasaan dihargai dan didorong untuk berpartisipasi; respons yang dirasakan siswa lainnya, guru, dan seluruh anggota sekolah; serta perasaan siswa menjadi bagian dari sekolah (Goodenow, 1993).

Anggota lingkungan sekolah yang terdiri dari guru dan teman sebaya dapat memberi dampak positif pada motivasi, keterlibatan, dan sense of belonging pada siswa dalam proses belajar (Kiefer, Alley, \& Ellerbrock, 2015). Anggota lingkungan sekolah yang mendukung dan dapat menerima siswa dengan senang hati dapat memperkuat belongingness pada diri siswa (Honda, Levett-Jones, Stone, \& Maguire, 2016) yang kemudian memberi dampak positif pada meningkatnya kepuasan hidup siswa (McMahon, Wernsman, \& Rose, 2009). Dengan kata lain semakin kuat belongingness pada siswa maka semakin puas mereka dengan hidupnya (Çikrikçi \& Başaran, 2017). 


\section{METODE}

Pada penelitian ini pendekatan yang digunakan adalah pendekatan kuantitatif dengan metode kausalitas untuk menguji pengaruh perubahan variasi nilai variabel X1 dalam hal ini yaitu academic emotions dan/atau variabel X2 yaitu school belonging terhadap variabel $\mathrm{Y}$ yaitu students' life satisfaction (Silalahi, 2009).

Populasi dalam penelitian ini adalah siswa SMP Negeri di kota Bandung. Merujuk pada data dari dapo. dikdasmen.kemdikbud.go.id, siswa SMP Negeri kota Bandung secara keseluruhan berjumlah sebanyak 56.398 siswa. Adapun jumlah sampel penelitian ini terdapat sebanyak 471 siswa yang diperoleh dengan menggunakan rumus Slovin dengan toleransi $10 \%$. Sampel tersebut diperoleh dengan menggunakan teknik cluster random sampling berdasarkan rayon sekolah yang terbagi menjadi 7 rayon.

Pengumpulan data penelitian ini dilakukan dengan metode kuesioner yan dibagikan secara langsung kepada partisipan. Instrumen yang digunakan dalam penelitian ini terdiri dari tiga instrumen. Pertama, instrumen untuk mengukur academic emotions menggunakan skala yang diadaptasi dari skala Achievement Emotions Questionnaire (AEQ) yang disusun oleh Pekrun dkk. tahun 2011 (Pekrun dkk., 2011). Kedua, instrumen untuk mengukur school belonging dengan menggunakan skala yang diadaptasi dari skala Psychological Sense of School Membership (PSSM) (Goodenow, 1993). Terakhir adalah instrumen untuk mengukur students' life satisfaction menggunakan skala yang diadaptasi dari Multidimensional Students' Life Satisfaction Scale (MSLSS) yang disusun oleh Huebner pada tahun 1994 (Huebner, 1994).

Ketiga instrumen penelitian ini menggunakan skala likert. Instrumen AEQ menggunakan lima pilihan jawaban (sangat tidak setuju, tidak setuju, netral, setuju, dan sangat setuju). Begitu juga dengan instrumen PSSM yang menggunakan lima pilihan jawaban (sangat tidak sesuai, tidak sesuai, netral, sesuai, dan sangat sesuai). Terakhir adalah instrumen MSLSS menggunakan enam pilihan jawaban (sangat tidak sesuai, tidak sesuai, cukup tidak sesuai, cukup sesuai, sesuai, dan sangat sesuai). Sebelum melakukan pengambilan data penelitian, peneliti melakukan proses expert judgement terhadap instrumen penelitian oleh ahli di bidang psikologi. Setelah itu, dilakukan uji coba alat ukur kepada 403 siswa SMP dan SMA. Dengan menggunakan data uji coba tersebut kemudian peneliti mengolahnya untuk mengetahui reliabilitas masing-masing instrumen dan validitas itemnya. Reliabilitas instrumen PSSM adalah sebesar 0.83 dan MSLSS sebesar 0.90. Hal ini berarti kedua instrumen memiliki reliabilitas yang sangat bagus. Adapun reliabilitas untuk instrumen AEQ dibagi menjadi 6 karena terdapat 6 skala di dalamnya. Terdapat 4 skala yang termasuk pada instrumen dengan reliabilitas yang bagus yaitu skala emosi positif yang berkaitan dengan kelas sebesar 0.77 , skala emosi positif yang berkaitan dengan belajar sebesar 0.76 , skala emosi positif yang berkaitan dengan tes sebesar 0.80, dan skala emosi negatif yang berkaitan dengan kelas sebesar 0.79. Sedangkan 2 skala AEQ lainnya termasu pada instrumen dengan 
reliabilitas sangat bagus yaitu skala emosi negatif yang berkaitan dengan belajar sebesar 0.85 dan skala emosi negatif yang berkaitan dengan tes sebesar 0.82 .

\section{HASIL}

Hasil perhitungan uji regresi linear menunjukkan bahwa emosi positif yang berkaitan dengan kelas $\left(\mathrm{r}^{2}=0.295, \mathrm{~B}=0.678, \mathrm{p}<0.05\right)$, emosi positif yang berkaitan dengan belajar $\left(\mathrm{r}^{2}=0.196, \mathrm{~B}=0.352, \mathrm{p}<0.05\right)$, dan emosi positif yang berkaitan dengan tes $\left(\mathrm{r}^{2}=0.165\right.$, $\mathrm{B}=0.381, \mathrm{p}<0.05)$ memiliki pengaruh terhadap students' life satisfaction. Melihat dari nilai koefisien determinasi $\left(\mathrm{r}^{2}\right)$ maka dapat diketahui bahwa masing-masing emosi positif yang berkaitan dengan kelas berpengaruh sebesar $29.50 \%$, emosi positif yang berkaitan dengan belajar berpengaruh sebesar $19.60 \%$, dan emosi positif yang berkaitan dengan tes berpengaruh sebesar $16.50 \%$.

Selanjutnya hasil perhitungan uji regresi linear menunjukkan bahwa emosi negatif yang berkaitan dengan kelas $\left(\mathrm{r}^{2}=0.122, \mathrm{~B}=-0.541, \mathrm{p}<0.05\right)$, emosi negatif yang berkaitan dengan belajar $\left(\mathrm{r}^{2}=0.154, \mathrm{~B}=-0.446, \mathrm{p}<0.05\right)$, dan emosi negatif yang berkaitan dengan tes $\left(\mathrm{r}^{2}=0.070, \mathrm{~B}=-0.317, \mathrm{p}<0.05\right)$ memiliki pengaruh terhadap students 'life satisfaction. Melihat dari nilai koefisien determinasi $\left(\mathrm{r}^{2}\right)$ maka dapat diketahui bahwa masing-masing emosi negatif yang berkaitan dengan kelas berpengaruh sebesar $12.20 \%$, emosi negatif yang berkaitan dengan belajar berpengaruh sebesar $15.40 \%$, dan emosi negatif yang berkaitan dengan tes berpengaruh sebesar $7 \%$.

Kemudian berlanjut pada hasil uji regresi linear yang menunjukkan bahwa school belonging berpengaruh secara signifikan pada students' life satisfaction $\left(\mathrm{r}^{2}=0.476, \mathrm{~B}=0.690\right.$, $\mathrm{p}<0.05)$. Melihat dari nilai koefisien determinasi $\left(\mathrm{r}^{2}\right)$ maka dapat diketahui bahwa school belonging berpengaruh sebesar $47.60 \%$ terhadap kepuasan hidup siswa. Sedangkan $52.40 \%$ lainnya dipengaruhi oleh faktor lain yang tidak diteliti pada penelitian ini.

Hasil uji regresi berganda juga menunjukkan ketika menggabungkan variabel school belonging dengan masing-masing emosi positif yaitu emosi positif yang berkaitan dengan kelas $\left(\mathrm{r}^{2}=0.520\right.$, B untuk emosi=0.309, B untuk school belonging $\left.=0.559, \mathrm{p}<0.05\right)$, emosi positif yang berkaitan dengan belajar $\left(\mathrm{r}^{2}=0.499\right.$, B untuk emosi=0.135, B untuk school belonging $=0.615, \mathrm{p}<0.05)$, dan emosi positif yang berkaitan dengan tes $\left(\mathrm{r}^{2}=0.492\right.$, B untuk emosi $=0.133$, B untuk school belonging $=0.630, \mathrm{p}<0.05$ ) memiliki pengaruh terhadap students' life satisfaction

Uji regresi berganda juga dilakukan pada emosi negatif. Hasil uji regresi berganda juga menunjukkan ketika menggabungkan variabel school belonging dengan masing-masing emosi negatif yaitu emosi negatif yang berkaitan dengan kelas $\left(\mathrm{r}^{2}=0.509\right.$, B untuk emosi=0.293, B untuk school belonging $=0.643, \mathrm{p}<0.05)$, emosi negatif yang berkaitan dengan belajar $\left(\mathrm{r}^{2}=0.527\right.$, B untuk emosi $=-0.264$, B untuk school belonging $\left.=0.630, \mathrm{p}<0.05\right)$, dan 
emosi negatif yang berkaitan dengan tes $\left(\mathrm{r}^{2}=0.500\right.$, B untuk emosi $=-0.188$, B untuk school belonging $=0.664, \mathrm{p}<0.05)$ memiliki pengaruh terhadap students' life satisfaction

\section{PEMBAHASAN}

Boekaerts (2007) menyebutkan bahwa siswa memiliki dua kepentingan di kelas yaitu meningkatkan bakat dan kemampuan yang dimiliki serta membantu mereka merasa bahagia. Rasa bahagia yang siswa rasakan ini tidak terlepas dari emosi positif yang dialami. Emosi positif yang dimaksud adalah enjoyment atau kenikmatan, hope atau harapan, dan pride atau bangga (Pekrun dkk., 2011).

Siswa yang merasa kesulitan dan tidak memiliki solusi terutama dalam hal akademik akan menganggap hambatan tersebut sebagai situasi yang membuatnya stres (Boekaerts, 2007). Siswa yang mengalami stres cenderung akan berakibat pada menurunnya kepuasan hidup mereka (Mitrofan \& Ciuluvică, 2012). Hal ini sejalan hasil penelitian yang menunjukkan bahwa stres yang disertai dengan emosi marah dan rasa permusuhan ternyata dapat menurunkan kepuasan hidup (Mitrofan \& Ciuluvică, 2012).

School belonging ini akan semakin kuat ketika anggota lingkungan sekolah dapat mendukung dan menerima siswa (Honda dkk., 2016) sehingga kemudian memberi dampak pada meningkatnya kepuasan hidup siswa (McMahon dkk., 2009). Ketika siswa semakin puas dengan segala hal yang bekaitan dengan sekolahnya, maka semakin puas juga hidupnya (Suldo dkk., 2013). Bahkan Slaten dkk. (2016) menegaskan bahwa sekolah juga menjadi tempat untuk memenuhi kebutuhan keterikatan atau belongingness siswa. Menurut teori hirarki kebutuhan hal ini disebut sebagai kebutuhan terhadap rasa cinta dan rasa memiliki (Maslow, 1943; Taormina \& Gao, 2013). Dalam memenuhi kebutuhannya tersebut siswa memiliki kebutuhan untuk mendapatkan afeksi seperti rasa cinta dan ketulusan dari teman, guru, dan anggota sekolahnya (Stangor, 2010; Suyono \& Mudjanarko, 2017). Ketika kebutuhan belongingness ini terpenuhi, khususnya yang terwujud dalam school belonging, maka kepuasan hidup siswa akan semakin memungkinkan untuk meningkat. Hal ini karena semakin banyak kebutuhan yang terpenuhi maka semakin puas hidup seseorang (Frisch, 1998).

.Kööts-Ausmees dkk. (2013) yang mengatakan bahwa individu yang cenderung merasakan emosi positif akan lebih puas dengan hidupnya. Kehadiran emosi positif pada siswa dapat dipengaruhi oleh karakter dan cara guru mengajar (Mainhard dkk., 2017). Karakter, kepedulian, perhatian, dan dukungan dari guru menjadi faktor yang memengaruhi kuat lemahnya school belonging pada siswa (Chhuon \& Wallace, 2012; Kiefer dkk., 2015). Tidak hanya interaksi dengan guru, interaksi siswa dengan teman-temannya di sekolah juga menjadi hal yang sangat menentukan terciptanya emosi positif pada siswa (Anttila, Pyhältö, Pietarinen, \& Soini, 2018; Lei, Cui, \& Chiu, 2018). 
Siswa merasakan berbagai emosi negatif yang kemudian disadari dapat menurunkan kepuasan hidup mereka (Mitrofan \& Ciuluvică, 2012). Dengan begitu mereka akan berusaha untuk mengatasi emosi negatif yang dirasakan (Boekaerts, 2007). Hal ini dapat diatasi dengan cara siswa melakukan interaksi dengan anggota sekolahnya yang diharapkan akan memberi dampak positif pada motivasi, keterlibatan, dan sense of belonging siswa dalam berbagai proses akademik (Kiefer dkk., 2015) hingga kemudian berpengaruh pada meningkatnya kepuasan hidup siswa (McMahon dkk., 2009).

Berdasarkan hasil penelitian ini maka dapat diketahui bahwa emosi yang paling banyak berkontribusi terhadap kepuasan hidup siswa adalah emosi positif yang berkaitan dengan kelas yaitu $29.50 \%$. Persentase ini masih lebih kecil dari kontribusi school belonging yang berpengaruh sebanyak $47.60 \%$ terhadap kepuasan hidup siswa. Selain itu dibuktikan juga bahwa semua tipe academic emotions (emosi positif yang berkaitan dengan kelas, emosi positif yang berkaitan dengan belajar, emosi positif yang berkaitan dengan tes, emosi negatif yang berkaitan dengan kelas, emosi negatif yang berkaitan dengan belajar, dan emosi negatif yang berkaitan dengan tes) dan school belonging juga berpengaruh terhadap kepuasan hidup siswa. Kontribusi terbesar diberikan oleh emosi negatif yang berkaitan dengan belajar dan school belonging yaitu sebesar $52.70 \%$.

\section{DAFTAR PUSTAKA}

Anttila, H., Pyhältö, K., Pietarinen, J., \& Soini, T. (2018). Socially Embedded Academic Emotions in School. Journal of Education and Learning, 7(3), 87-101. https://doi.org/10.5539/jel.v7n3p87

APA. (2002). Developing Adolescents: A Reference for Professionals. Washington: American Psychological Association. https://doi.org/10.1177/109821408100200104

Baș, A. U., \& Yurdabakan, İ. (2017). The Predictive Value of Resilience and School Climate in Life Satisfaction among Middle School Students. Mehmet Akif Ersoy Üniversitesi Eğitim Fakültesi Dergisi, 41, 202-214. https://doi.org/10.21764/efd.32175

Boekaerts, M. (2007). Understanding Students' Affective Processes in the Classroom. In R. Pekrun \& P. A. Schutz (Eds.), Emotion in Education. Burlington: Elsevier Inc.

Chhuon, V., \& Wallace, T. L. (2012). Creating connectedness through being known: Fulfilling the need to belong in U.S. high schools. Youth \& Society, 46(3), 379-401. https://doi.org/10.1177/0044118X11436188

Çikrikçi, Ö., \& Başaran, G. (2017). The effects of attachment styles and belongingness on life satisfaction among adolescents. International Journal of Happiness and Development, 3(3), 241-255. https://doi.org/10.1504/IJHD.2017.084073

Coon, D., \& Mitterer, J. O. (2014). Psychology: A Journey (Fifth). Belmont: Wadsworth. 
Durak, M., Senol-Durak, E., \& Gencoz, T. (2010). Psychometric properties of the satisfaction with life scale among Turkish university students, correlational officers, and elderly adults. Social Indicators Research, 99, 413-429. https://doi.org/ 10.1007/s11205-010-9589-4

Frisch, M. B. (1998). Quality of life therapy and assessment in health care. Clinical Psychology: Science and Practice, 5, 19-40.

Goetz, T., Haag, L., Lipnevich, A. A., Keller, M. M., Frenzel, A. C., \& Collier, A. P. M. (2014). Between-domain relations of students' academic emotions and their judgments of school domain similarity. Frontiers in Psychology, 5(1153), 1-14. https://doi.org/ 10.3389/fpsyg.2014.01153

Goodenow, C. (1993). the Psychological Sense of School Membership Among Adolescents: Scale Development and Educational Correlates. Psychology in the Schools, 30, 79-90. https://doi.org/10.1177/095968369100100211

Honda, K., Levett-Jones, T., Stone, T., \& Maguire, J. (2016). Japanese nursing students' sense of belonging: A story of Uchi (insider) and Soto (outsider). Nurse Education in Practice, 20, 85-92. https://doi.org/10.1016/j.nepr.2016.07.004

Huebner, E. S. (1991). Initial Development of the Student's Life Satisfaction Scale. School Psychology International, 12, 231-240. https://doi.org/10.1177/0143034391123010

Huebner, E. S. (1994). Preliminary Development and Validation of a Multidimensional Life Satisfaction Scale for Children. Psychology Assessment, 6(2), 149-158.

Huebner, E. S., Laughlin, J. E., Ash, C., \& Gilman, R. (1998). Further Validation of the Multidimensional Students' Life Satisfaction Scale. Journal of Psychoeducational Assessment, 16, 118-134. https://doi.org/10.1177/073428299801600202

Hughes, J. N., Im, M. H., \& Allee, P. J. (2016). Effect of school belonging trajectories in grades $6-8$ on achievement: Gender and ethnic differences achievement : Gender and ethnic differences. Journal of School Psychology, 53(2015), 493-507. https://doi.org/10.1016/j.jsp.2015.08.001

Kiefer, S. M., Alley, K. M., \& Ellerbrock, C. R. (2015). Teacher and Peer Support for Young Adolescents ' Motivation, Engagement, and School Belonging. Research in Middle Level Education (RMLE) Online, 38(8). https://doi.org/10.1080/19404476. 2015.11641184

Kööts-Ausmees, L., Realo, A., \& Allik, J. (2013). The Relationship Between Life Satisfaction and Emotional Experience in 21 European Countries. Journal of CrossCultural Psychology, 44(2), 223-244. https://doi.org/10.1177/0022022112451054

Kuppens, P., Realo, A., \& Diener, E. (2008). The Role of Positive and Negative Emotions in Life Satisfaction Judgment Across Nations. Journal of Personality and Social Psychology, 95(1), 66-75. https://doi.org/10.1037/0022-3514.95.1.66 
Lei, H., Cui, Y., \& Chiu, M. M. (2018). The Relationship between Teacher Support and Students' Academic Emotions: A Meta-Analysis. Frontiers in Psychology, 8, 1-12. https://doi.org/10.3389/fpsyg.2017.02288

Li, J., \& Zhao, D. (2014). The Relationship among Positive Emotion, Meaning in Life and Life Satisfaction in Master Students. Advances in Psychology, 4, 1-4.

Mainhard, T., Oudman, S., Hornstra, L., Bosker, R. J., \& Goetz, T. (2017). Student emotions in class: The relative importance of teachers and their interpersonal relations with students. Learning and Instruction, 1-11. https://doi.org/10.1016/j.learninstruc. 2017.07.011

Maslow, A. H. (1943). A theory of human motivation. Psychological Review, 50(4), 370396. https://doi.org/10.1037/h0054346

McCabe, K., Bray, M. A., Kehle, T. J., Theodore, L. A., \& Gelbar, N. W. (2011). Promoting Happiness and Life Satisfaction in School Children. Canadian Journal of School Psychology, 26(3), 177-192. https://doi.org/10.1177/0829573511419089

McMahon, S. D., Wernsman, J., \& Rose, D. S. (2009). The Relation of Classroom Environment and School Belonging to Academic Self-Efficacy among Urban Fourthand Fifth-Grade Students. The Elementary School Journal, 109(3), 267-281.

Mitrofan, N., \& Ciuluvică, C. (2012). Anger and hostility as indicators of emotion regulation and of the life satisfaction at the beginning and the ending. Procedia - Social and Behavioral Sciences, 33, 65-69. https://doi.org/10.1016/j.sbspro.2012.01.084

Na'imah, T. (2012). Pendidikan Karakter (Kajian Dari Teori Ekologi Perkembangan). In Prosiding Seminar Nasional Psikologi Islami (pp. 159-166).

Pandey, S., Dave, S., \& Chandra, A. K. (2017). Emotional Stability: A study on adolescent students of Bhilai, India. Recearch Journal Of Management Sciences, 6(9), 17-20.

Pekrun, R., Goetz, T., Frenzel, A. C., Barchfeld, P., \& Perry, R. P. (2011). Measuring emotions in students' learning and performance: The Achievement Emotions Questionnaire (AEQ). Contemporary Educational Psychology, 36(1), 36-48.

Pekrun, R., Goetz, T., Titz, W., \& Perry, R. P. (2002a). Academic Emotions in Students' Self-Regulated Learning and Achievement: A Program of Qualitative and Quantitative Research. Educational Psychologist, 37(2), 91-106. https://doi.org/10.1207/S15326985EP3702

Pekrun, R., Goetz, T., Titz, W., \& Perry, R. P. (2002b). Positive Emotions in Education. In E. Frydenberg (Ed.), Beyond Coping: Meeting Goals, Visions and Challenges (pp. 149173). Oxford: Oxford University Press. https://doi.org/10.1207/S15326985EP3702

Santrock, J. W. (2011). Perkembangan Masa Hidup. Jakarta: Penerbit Erlangga. 
Seyitoğlu, F., \& Çevik, B. (2016). The impacts of student and life satisfaction on tourism students' perceived sense of belonging. Journal of Teaching in Travel \& Tourism, 1-20. https://doi.org/10.1080/15313220.2016.1197083

Shaffer, D. R., \& Kipp, K. (2010). Developmental Psychology (Edisi 8). Belmont: Wadsworth.

Silalahi, U. (2009). Metode Penelitian Sosial. Bandung: PT Refika Aditama.

Slaten, C. D., Ferguson, J. K., Allen, K.-A., Brodrick, D.-V., \& Waters, L. (2016). School Belonging: A Review of the History, Current Trends, and Future Directions. The Educational and Developmental Psychologist, 33(1), 1-15. https://doi.org/10.1017/ edp. 2016.6

Stangor, C. (2010). Introduction to Psychology. Saylor Academy. Retrieved from https://www.saylor.org/site/textbooks/Introduction to Psychology.pdf

Suldo, S. M., Thalji-Raitano, A., Hasemeyer, M., Gelley, C. D., \& Hoy, B. (2013). Understanding Middle School Students Life Satisfaction: Does School Climate Matter? Applied Research Quality Life, 8, 169-182. https://doi.org/10.1007/s11482-012-9185-7

Suyono, J., \& Mudjanarko, S. W. (2017). Motivation engineering to empolyee by employees: Abraham Maslow Theory. Journal of Education, Teaching, and Learning, 2(1), 86-92.

Taormina, R. J., \& Gao, J. H. (2013). Maslow and the Motivation Hierarchy: Measuring Satisfaction of the Needs. American Journal of Psychology, 126(2), 155-177.

Yiğit, A., Özpolat, A. R., \& Kandemir, M. (2014). Emotion Regulation Strategies as a Predictor of Life Satisfaction in University Students. Psychology, (5), 523-532. https://doi.org/10.4236/psych.2014.56062 